\title{
Comparison between cold water immersion therapy (CWIT) and light emitting diode therapy (LEDT) in short-term skeletal muscle recovery after high-intensity exercise in athletes-preliminary results
}

\author{
Ernesto Cesar Leal Junior • Vanessa de Godoi • José Luis Mancalossi • \\ Rafael Paolo Rossi • Thiago De Marchi • Márcio Parente • Douglas Grosselli • \\ Rafael Abeche Generosi • Maira Basso • Lucio Frigo • Shaiane Silva Tomazoni • \\ Jan Magnus Bjordal • Rodrigo Álvaro Brandão Lopes-Martins
}

Received: 15 June 2010 / Accepted: 4 October 2010 / Published online: 19 November 2010

(C) The Author(s) 2010. This article is published with open access at Springerlink.com

\begin{abstract}
In the last years, phototherapy has becoming a promising tool to improve skeletal muscle recovery after exercise, however, it was not compared with other modalities commonly used with this aim. In the present study we compared the short-term effects of cold water immersion therapy (CWIT) and light emitting diode therapy (LEDT) with placebo LEDT on biochemical markers related to skeletal muscle recovery after high-intensity exercise. A randomized double-blind placebo-controlled crossover trial was performed with six male young futsal
\end{abstract}

E. C. Leal Junior $(\bowtie) \cdot$ R. Á. B. Lopes-Martins

Center for Research and Innovation in Laser,

Nove de Julho University (UNINOVE),

Rua Vergueiro, 235,

01504-001 São Paulo, SP, Brazil

e-mail: ernesto.leal.junior@gmail.com

R. Á. B. Lopes-Martins

e-mail: rmartins@icb.usp.br

V. de Godoi $\cdot$ R. P. Rossi $\cdot$ S. S. Tomazoni

R. Á. B. Lopes-Martins

Laboratory of Pharmacology and Experimental Therapeutics, Department of Pharmacology,

Institute of Biomedical Sciences,

University of São Paulo (USP),

Av. Lineu Prestes, 1524,

05508-000 São Paulo, SP, Brazil

V. de Godoi

e-mail: godoi.vane@gmail.com

R. P. Rossi

e-mail: rossi.rafael@gmail.com

S. S. Tomazoni

e-mail: shaiane.tomazoni@gmail.com athletes. They were treated with CWIT $\left(5^{\circ} \mathrm{C}\right.$ of temperature [SD $\pm 1^{\circ}$ ), active LEDT (69 LEDs with wavelengths 660/ $850 \mathrm{~nm}, 10 / 30 \mathrm{~mW}$ of output power, $30 \mathrm{~s}$ of irradiation time per point, and $41.7 \mathrm{~J}$ of total energy irradiated per point, total of ten points irradiated) or an identical placebo LEDT 5 min after each of three Wingate cycle tests. Pre-exercise, post-exercise, and post-treatment measurements were taken of blood lactate levels, creatine kinase (CK) activity, and Creactive protein (CRP) levels. There were no significant differences in the work performed during the three Wingate

\footnotetext{
J. L. Mancalossi • T. De Marchi • D. Grosselli • M. Basso Laboratory of Human Movement (LMH), Sports Medicine Institute (IME), University of Caxias do Sul (UCS),

Rua Francisco Getúlio Vargas, 1130,

95070-560 Caxias do Sul, RS, Brazil

J. L. Mancalossi

e-mail: jlmfisio@hotmail.com

T. De Marchi

e-mail: thiagomarchi@gmail.com

D. Grosselli

e-mail: douglasgrosseli@hotmail.com

M. Basso

e-mail: mairinhabasso@pop.com.br

T. De Marchi

Laboratory of Oxidative Stress and Antioxidants,

Institute of Biotechnology, University of Caxias do Sul (UCS),

Caxias do Sul, RS, Brazil

R. A. Generosi

Federal University of Rio Grande do Sul,

Porto Alegre, RS, Brazil

e-mail: rafaelgenerosi@hotmail.com
} 
tests $(p>0.05)$. All biochemical parameters increased from baseline values $(p<0.05)$ after the three exercise tests, but only active LEDT decreased blood lactate levels $(p=0.0065)$ and CK activity $(p=0.0044)$ significantly after treatment. There were no significant differences in CRP values after treatments. We concluded that treating the leg muscles with LEDT 5 min after the Wingate cycle test seemed to inhibit the expected post-exercise increase in blood lactate levels and CK activity. This suggests that LEDT has better potential than $5 \mathrm{~min}$ of CWIT for improving short-term post-exercise recovery.

Keywords LEDT $\cdot$ CWIT $\cdot$ Skeletal muscle $\cdot$ Skeletal muscle recovery $\cdot$ Skeletal muscle damage $\cdot$ Sports

\section{Introduction}

The scientific interest in sports recovery modalities has been increasing in the last years. Studies have been investigating the effects of modalities on subjective outcomes like post-exercise well-being, objective outcomes like physical performance and surrogate outcomes like biochemical markers related to recovery [1, 2]. Blood lactate levels, creatine kinase (CK) activity, and C-reactive protein (CRP) levels are commonly used as biochemical markers of skeletal muscle recovery [3].

Blood lactate concentration is used to monitor and plan training, and it is usually assessed by portable devices. Although some authors [4-6] discuss the validity of the blood lactate concentration as a parameter to determine the

\section{Frigo}

Biological Sciences and Health Center,

Cruzeiro do Sul University,

Av. Dr. Ussiel Cirilo, 225,

08060-070 São Miguel Paulista, São Paulo, SP, Brazil

e-mail: luciofrigo@uol.com.br

\section{J. M. Bjordal}

Section for Physiotherapy Science,

Department of Public Health and Primary Health Care,

Faculty of Medicine and Dentistry, University of Bergen,

Mollendalsvn 6,

5009 Bergen, Norway

e-mail: jan.magnus.bjordal@hib.no

\section{J. M. Bjordal}

Center for Evidence-Based Practice, Bergen University College,

Bergen, Norway

\section{Parente}

Post Graduate Program of Rehabilitation Sciences,

Nove de Julho University (UNINOVE),

Rua Vergueiro, 235,

01504-001 São Paulo, SP, Brazil

e-mail: parente10@yahoo.com muscle recovery after exercise, this biochemical marker has been widely used for this purpose [7-9].

Muscle damage can occur after strenuous sporting activities [10]. Activity-related changes in CK plasma enzyme activity can indicate an emerging state of muscle damage [11]. Increased CK activity has been reported after strenuous exercise [12]. Athletes normally have higher plasma CK activity at rest than non-trained individuals [13], but their post-exercise CK activity increases to a lesser extent than for non-athletes [14].

High-intensity and repetitive skeletal muscle contractions can also induce an inflammatory response in muscle tissue, which is related to the early development of skeletal muscle damage $[15,16]$. CRP is a commonly used marker of systemic inflammation [17] that has also been used to investigate the level of inflammation post-exercise [16-18].

A large amount of therapeutic modalities are used after sports activities to improve skeletal muscle recovery, the most commonly used modalities are: active recovery [7-10], cryotherapy $[10,19,20]$, massage $[8,21]$, contrast heat therapy (use of hot and cold water immersion) [22, 23], hydrotherapy [24], stretching [4], and electric stimulation [25]. However, the scientific evidence behind these modalities is limited.

Cold water immersion therapy (CWIT) is a modality that uses immersion of a body part in water with temperature below $15^{\circ} \mathrm{C}$. It is one of the most popular therapeutic modalities used to improve muscle recovery after high-intensity exercise [4]. However, there is only anecdotal scientific information regarding the effectiveness of this therapy [26].

Skeletal muscle recovery is a novel area of research in phototherapy. Recent studies with low-level laser therapy (LLLT) [27] and light emitting diode therapy (LEDT) [28, 29] have shown positive results for skeletal muscle recovery when these therapies were applied before exercise. If the intention is to cover a large part of the exercised muscle, then multi-diode cluster probes with several visible red LED diodes or infrared laser diodes may be more suitable for this purpose. The irradiation of tissue at different levels may represent a therapeutic advantage. For instance, red diodes could promote increased microcirculation in skin, and infrared diodes could increase ATP synthesis and decrease oxidative stress in exercised muscles, leading to improvement in short-term recovery.

In sports settings, the therapeutic modalities are normally used after exercise sessions and usually the time available to perform the treatment is limited, especially in sports with a low interval time between sets such as: volleyball, tennis, handball, and others. Although CWIT has a relative low cost, the time required for therapists to prepare CWIT is time-consuming. Additionally, the water and ice used in CWIT can only be used once, and it is relatively difficult to control the temperature during the treatment. On the other hand, LEDT devices can be used several times without 
lengthy preparations, but they also have a considerably higher cost than water and ice.

For these reasons, we decided to investigate and compare the short-term effects of $5 \mathrm{~min}$ of CWIT and 5 min of LEDT in biochemical markers related to skeletal muscle recovery after Wingate cycle test in a homogeneous sample of young athletes in a randomized crossover design.

\section{Methods}

We performed a cross-over randomized double-blinded placebo-controlled trial. The study was approved by the ethics committee of the Vale do Paraíba University (Protocol Number H06/CEP/2008). All subjects or one of their parents signed written informed consent forms before their participation in the experiment.

\section{Inclusion criteria}

1. Male futsal players at highest national level (Brazil);

2. Active futsal player for at least 3 years and with at least 5 days of training per week;

3. Age between 17 and 25 years.

\section{Exclusion criteria}

1. Any musculoskeletal injury to the hip, knee, or ankle regions in the previous 2 months;

2. Participation in less than $80 \%$ of the regularly scheduled physical training and futsal sessions for the futsal team;

3. Players using any kind of nutritional supplements or pharmacological agents.

\section{Material}

Six volunteers were recruited among young male futsal players $(n=6)$ from Brazil at the highest national sporting level. Sample size was determined based in previous studies that used samples ranging 6 to 11 volunteers per group $[27,28,30]$.

\section{Randomization procedure}

Participants were scheduled to receive either CWIT, active LEDT, or placebo LEDT in a random manner after each of three exercise tests. Randomization was performed by a simple drawing of lots (A, B, or C) which determined if participants should receive CWIT, active LEDT, or placebo LEDT in the first session. The randomization procedure was administered by an assistant not involved in the experiment. The allocation code was then delivered to a technician who preset the LED control unit in active or placebo LEDT mode. He then delivered the preset unit to the therapist. The technician was instructed not to communicate the type of LED treatment given to either the patients, the therapist, or the observers. Thus, the allocation to LEDT was concealed to participants, therapist, and observers.

Blinding procedure

Careful attention was given to the blinding procedure and several measures were taken to ensure complete blinding. It is not possible to blind CWIT to the patients or therapists, but both therapists and patients were blinded to whether active LEDT or placebo LEDT was administered. The LEDT device was only activated after the LED cluster had been placed on the skin, and the cluster probe was not removed before the irradiation was over and the LED cluster was deactivated. This procedure hides the LEDs beam from sight for both the therapist and the participants. To further ensure blinding, therapists and participants used dark goggles for eye protection. Observers and analysts were blinded to whichever of the three treatments were given.

Test procedures

Period of evaluation All procedures were performed with the room temperature at $24^{\circ} \mathrm{C} \pm 1^{\circ}$ and relative humidity at $60 \% \pm 3 \%$. Care was taken in obtaining standardization in the execution of the exercise test protocols. Exercise tests were performed with a standard sitting position at approximately the same time of the day (to control for the circadian rhythm). The performance of the exercise tests took place in three sessions 1 week apart (day 1 , day 8 , and day 15) at the same day of the week (Monday) in the same period of the day (between 14:30 and 17:30). Any hard physical activity (such as training sessions or matches) was not permitted in the weekend and in the morning before the testing. The timeline of the experiment is shown in Fig. 1.

Fatigue test protocol At the first session (day 1), second session (day 8), and third session (day 15) of the study, basal blood measurements (blood lactate, creatine kinase, and C-reactive protein) were obtained for each subject. Immediately afterwards, the cycle test observer instructed the athletes and supervised them while conducting a series of muscle-stretching exercises. The stretching exercises involved all the major muscles of the lower extremities (one round of $60 \mathrm{~s}$ for each muscle group). Then, the observer seated each subject on the ergometer cycle and fixed their feet to the pedals. Instruction of the Wingate test was then delivered to the athletes. It consists of cycling at maximum 


\section{Flowchart with timeline of the study}

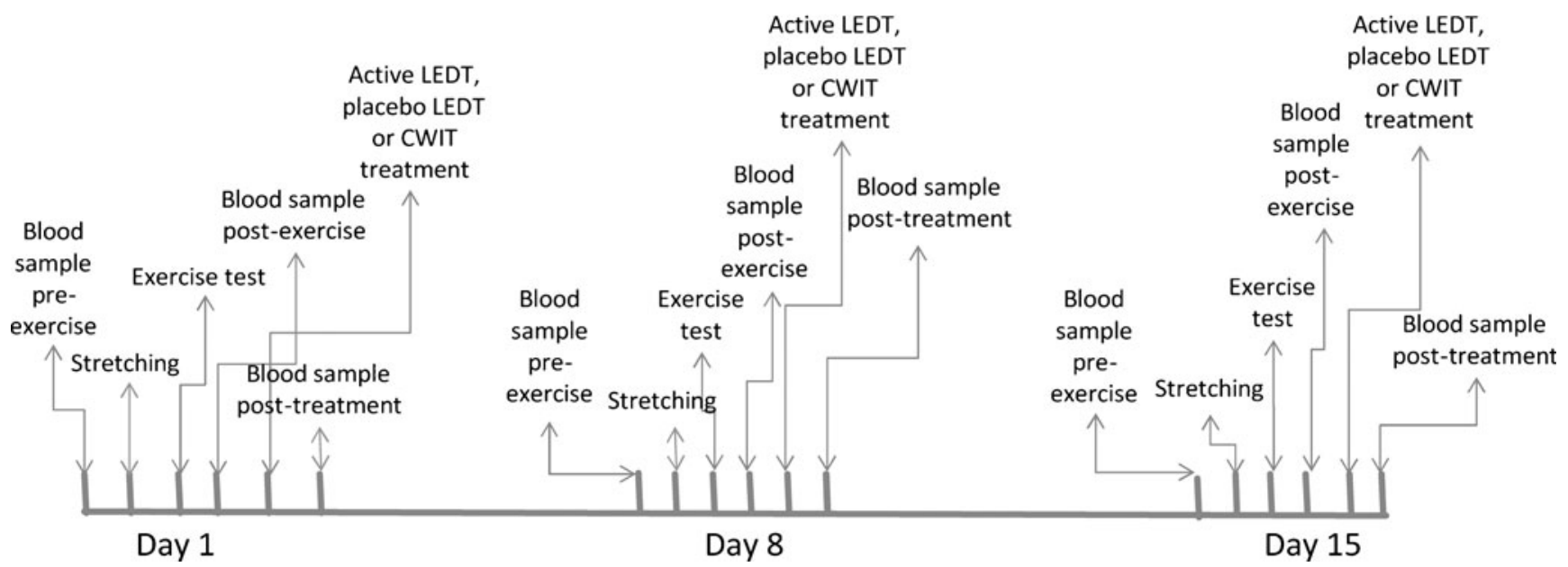

Fig. 1 Time flow chart of the study

speed for $30 \mathrm{~s}$ against a load of $7.5 \%$ of the respective athletes' body weight.

\section{Treatment protocols}

At all sessions (day 1, day 8, and day 15), the participants received a single treatment of active LEDT, placebo LEDT (both using a Cluster with 34 LED diodes of $660 \mathrm{~nm}$ and 35 LED diodes of $850 \mathrm{~nm}$ manufactured by THOR ${ }^{\circledR}$ Photomedicine, London, United Kingdom) or CWIT according to the result of the randomization procedure. Active LEDT or placebo LEDT were administered exactly 5 min after the exercise test, and was administered by a blinded therapist. The LED cluster was not turned on before the tip of the cluster was put in contact with the skin. The mm. triceps surae received LEDT irradiation in only one site in the center of the muscle belly, while mm. rectus femoris and hamstrings muscle belly was divided into two irradiation sites evenly distributed along the ventral middle line of the muscle belly in order to deliver LEDT irradiation to most of the muscle belly. The LEDT irradiation was performed bilaterally, and $30 \mathrm{~s}$ of irradiation was performed in each site, and thus ten sites (five per lower limb) in total were irradiated with a total LEDT irradiation time of $5 \mathrm{~min}$. The chosen LEDT parameters were based on our previous study where LEDT before Wingate test showed significant effects in decreasing biochemical markers of muscle damage [28]. The sites used to perform active and placebo LEDT are shown in Fig. 2.

Irradiation with LEDT was performed in contact mode with the probe held stationary with slight pressure at a $90^{\circ}$ angle to the skin surface. The parameters for the LEDT are summarized in Table 1.

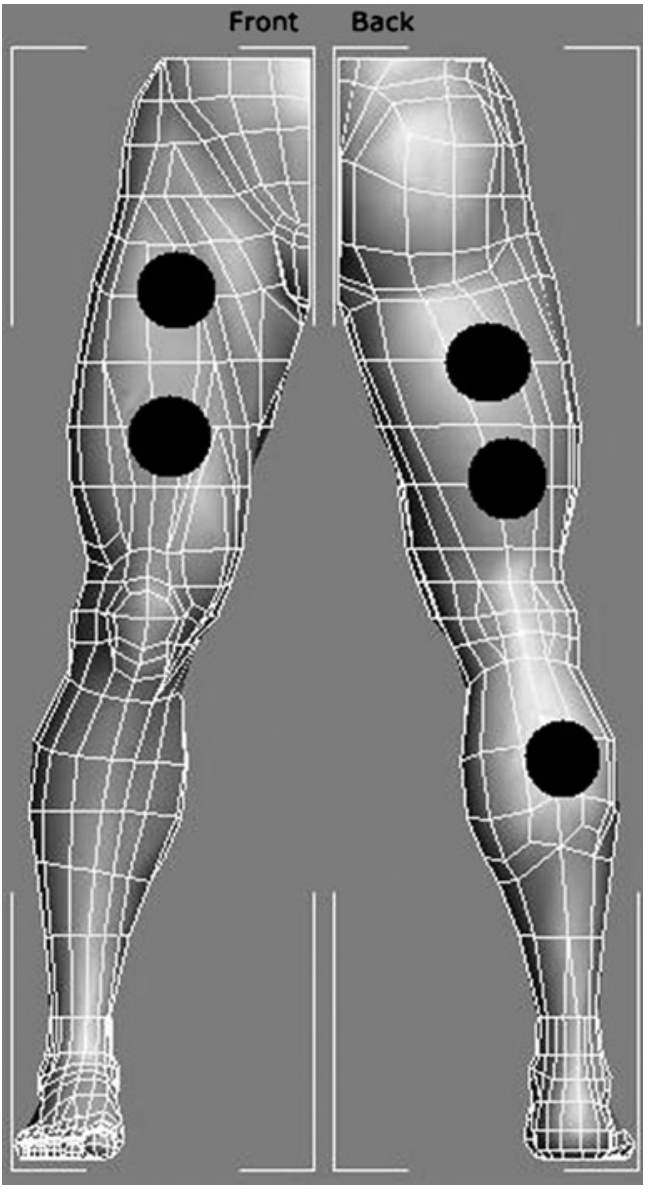

Fig. 2 Irradiation points (in black circles) used for active LEDT or placebo LEDT 
Table 1 Parameters for LEDT

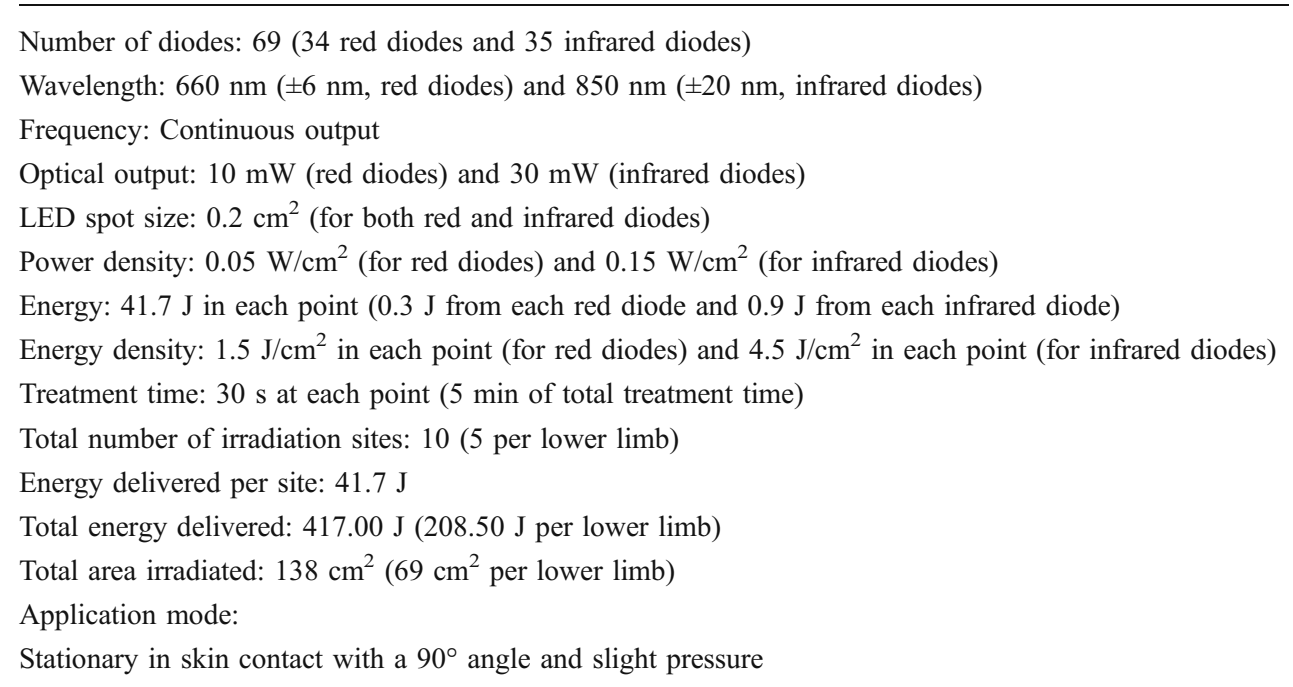

The CWIT was performed $5 \mathrm{~min}$ after the exercise test was completed. Subjects were lowered in a standing position inside a container with 501 of cold water (and ice cubes) at $5^{\circ} \mathrm{C}\left( \pm 1^{\circ}\right)$ for $5 \mathrm{~min}$, with the lower limbs immersed up to immediately below the gonadal region. The temperature was kept constant during the treatment and monitored with a thermometer.

Blood samples for blood lactate, CK, and CRP analysis

The blood lactate levels were measured in blood samples taken from the futsal players. Possible muscle damage and inflammation were indirectly measured in the futsal athletes by the CK activity and CRP levels, respectively. In order to measure these parameters, a qualified nurse (blinded to group allocation) performed aseptic cleaning of the ventral side of the dominant arm and took one sample before the stretching and exercise test (pre-exercise), another blood sample $3 \mathrm{~min}$ after the exercise test (post-exercise) and another blood sample exactly $10 \mathrm{~min}$ after treatments (20 min after the exercise test) were completed (post-treatment). The samples were frozen and after 1 week of the end of each phase the blood analysis were performed with infrared spectrophotometry, using a spectrophotometer $\left(\right.$ FEMTO $^{\circledR}$, Brazil) and specific kits for analysis of blood lactate (Bioclin ${ }^{\circledR}$, Brazil) and CK (Labtest ${ }^{\circledR}$, Brazil). The analysis of CRP was performed by agglutination method using a specific analysis kit (Wiener Laboratorios ${ }^{\circledR}$, Argentina). All blood analyses were performed by an observer who was blinded to treatment allocations.

\section{Statistical analysis}

Group means and their respective standard deviations were calculated. An ANOVA test with Tukey-Kramer post-test was used to test if there was a significant difference in baseline values and also in change post-exercise and posttreatment between active LEDT, placebo LEDT, and CWIT. An additional responder analysis for the combined dichotomized results of the three biochemical tests was planned with a Mantel Haenszel test for relative risk ratio. The significance level was set at $p<0.05$.

\section{Results}

Six healthy male young high-level futsal players were recruited who met the inclusion criteria. Their average age was $20.67( \pm 2.96)$ years old, and their body weight was a mean of $64.63 \mathrm{~kg}( \pm 7.34)$ and body height was $174.97 \mathrm{~cm}$ $( \pm 8.71)$.

There were no significant differences $(p>0.05)$ in the peak power $\left(12.00 \mathrm{~W} . \mathrm{kg}^{-1} \pm 0.36\right.$ - placebo LEDT; $12.70 \mathrm{~W}$.

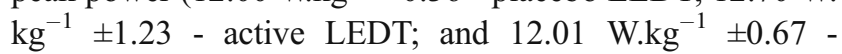
CWIT) and mean power (9.39 W. $\mathrm{kg}^{-1} \pm 0.48$ - placebo LEDT; $9.98 \mathrm{~W} . \mathrm{kg}^{-1} \pm 1.29$ - active LEDT; and $9.42 \mathrm{~W} . \mathrm{kg}^{-1}$ \pm 0.59 - CWIT) in the Wingate cycle tests. The results are summarized in Figs. 3 and 4.

Similarly, no significant differences were found for $\mathrm{CK}$ activity at the pre-exercise test $\left(90.55 \mathrm{U}^{-1} \mathrm{l}^{-1} \pm 20.28\right.$ - placebo LEDT; $92.30 \mathrm{U}^{-1}{ }^{-1} \pm 19.67$ - active LEDT; and 91.29 ${\mathrm{U} .1^{-1}}^{-1}$ \pm 20.49 - CWIT) $(p>0.05)$. CK activity increased after all three exercise tests but without any significant differences between the three test sessions $(p>0.05)$. After treatments, only active LEDT decreased CK activity significantly from post-exercise values $(p=0.0065)$. Placebo LEDT and CWIT did not significantly decrease CK activity $(p>0.05)$.

Blood lactate levels at the pre-exercise tests $\left(2.30 \mathrm{mmol}^{-1}\right.$ \pm 0.48 - placebo LEDT; $2.09 \mathrm{mmol}^{-1} \pm 0.65$ - active LEDT; and $2.13 \mathrm{mmol}^{-1} \pm 0.44$ - CWIT) were also similar with no 


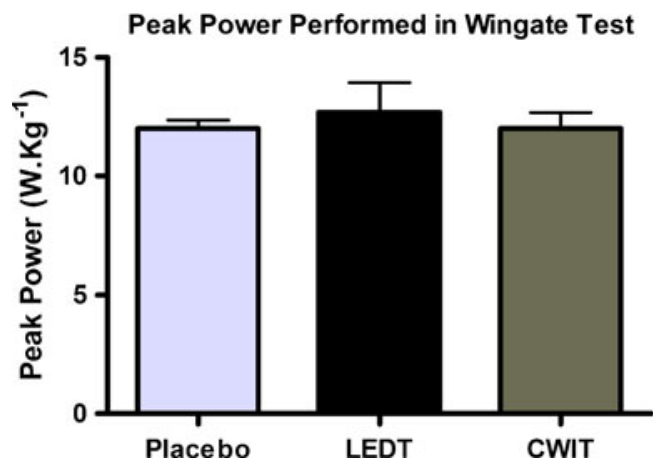

Fig. 3 Peak power performed by athletes in Wingate test at three exercise sessions. No difference was observed between tests. Error bars indicate standard deviations

significant differences between the sessions ( $p>0.05$ ). Postexercise blood lactate levels increased from pre-exercise test values in all three test sessions, without any significant difference $(p>0.05)$ between sessions. There were no significant differences $(p>0.05)$ in changes of blood lactate from post-exercise values to post-treatment with placebo LEDT and CWIT. However, active LEDT significantly decreased $(p=0.0044)$ the change in blood lactate levels from post-exercise values.

CRP levels did not change significantly $(p>0.05)$ from the pre-exercise values $\left(1,068.65 \mathrm{mg} . \mathrm{dl}^{-1} \pm 578.98\right.$ placebo LEDT; $1,112.35 \mathrm{mg}$.dl ${ }^{-1} \pm 546.62$ - active LEDT; and 1,087.52 mg.dl ${ }^{-1} \pm 534.02-$ CWIT). In all sessions the CRP levels increased after exercise, but without any statistically significant difference $(p>0.05)$ between the three sessions. None of the treatments decreased the CRP levels significantly $(p>0.05)$ from post-exercise values. However, a tendency to decrease from baseline values was observed for active LEDT without statistical significance. The results of change in biochemical markers are summarized in Table 2.

In the responder analysis, the relative risk for a positive response was borderline significant $(p=0.05)$ for active LEDT over placebo $\mathrm{RR}=1.67$ [95\% CI 1.00-1.67], but there were no significant differences for any of the other treatment comparisons (Table 3).

\section{Discussion}

This is the first time we have applied LEDT (or LLLT) after the performance a high-intensity exercise test. In our previous experiments, we applied LEDT or LLLT before the exercise tests. It is also the first time we have compared the effects of LEDT (or LLLT) with another active treatment (CWIT). Firstly, it is important to mention that no differences were observed in performance of futsal athletes or in baseline values of biochemical markers between three exercise tests. This was done to ensure that their levels of exhaustion were comparable, and it allows us to assume that the differences observed in biochemical markers were promoted by the recovery modalities. Another important point is that LEDT not only induced significantly greater reductions in CK activity and blood lactate levels, but the reductions occurred seemingly irrespective of high or low post-treatment values. This indicates that the greater difference in change in the LEDT group cannot be explained as a "regression to the mean" phenomenon, but suggests that LEDT causes a true reduction in the levels of these biochemical markers.

CWIT did not change any of the biochemical markers of recovery employed in this study. Several procedural factors could contribute to the non-significant result such as too short time of treatment $(5 \mathrm{~min})$ and non-optimal water temperature $\left(5^{\circ} \mathrm{C} \pm 1^{\circ}\right)$. However, previous studies investigating the effects of CWIT in recovery after exercises have used a variety of parameters, and no consensus seem to exist for optimal treatment parameters.

Halson et al. [3] did a randomized cross-over study (with 11 male endurance trained cyclists), but found no significant difference between CWIT $\left(11.5^{\circ} \mathrm{C}\right)$ and passive recovery $\left(24.2^{\circ} \mathrm{C}\right)$ in biochemical markers related to recovery (including blood lactate, CK, and CRP) after cycling exercise. Howatson et al. [20] performed a study with 16 male subjects to evaluate the effects of $12 \mathrm{~min}$ of CWIT $\left(15^{\circ} \mathrm{C}\right)$ in muscle recovery after exercise. There were no significant differences between cold water immersion and control group (12 min seated rest) in maximal voluntary contraction (MVC), DOMS, CK, thigh girth, and range of motion (ROM). However, the CWIT parameters employed in these studies were very different that we tested.

Sellwood et al. [19] tested the effects of 3 min (three sets of $1 \mathrm{~min}$, with an interval of $1 \mathrm{~min}$ between sets) CWIT $\left(5^{\circ} \mathrm{C} \pm 1^{\circ}\right)$ and compared with $3 \mathrm{~min}$ (three sets of $1 \mathrm{~min}$, with an interval of $1 \mathrm{~min}$ between sets) of immersion in

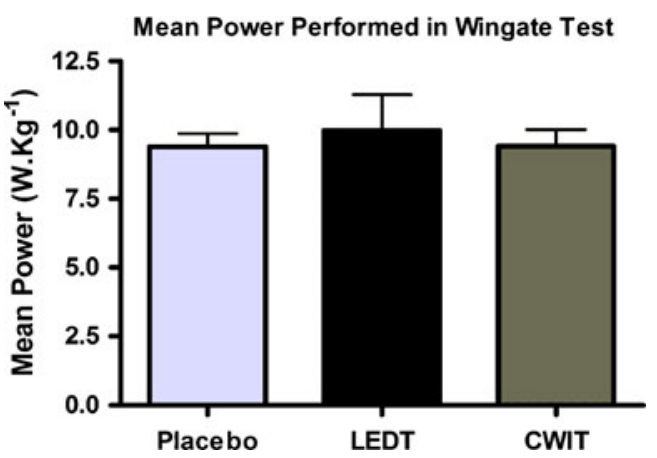

Fig. 4 Mean power performed by athletes in Wingate test at three exercise sessions. No difference was observed between tests. Error bars indicate standard deviations 
Table 2 Change in biochemical markers related to skeletal muscle recovery

\begin{tabular}{|c|c|c|c|c|c|c|}
\hline & \multicolumn{2}{|l|}{ Placebo } & \multicolumn{2}{|l|}{ LEDT } & \multicolumn{2}{|l|}{ CWIT } \\
\hline & Post-exercise & Post-treatment & Post-exercise & Post-treatment & Post-exercise & Post-treatment \\
\hline \multirow[t]{2}{*}{$\mathrm{CK}\left(\mathrm{U} .1^{-1}\right)$} & 4.73 & -1.72 & 15.22 & $-8.55 * *$ & 1.70 & -3.45 \\
\hline & \pm 7.92 & \pm 21.57 & \pm 13.42 & \pm 9.56 & \pm 14.91 & \pm 13.67 \\
\hline \multirow[t]{2}{*}{ Lactate $\left(\mathrm{mmol} .1^{-1}\right)$} & 11.00 & 9.17 & 16.00 & $10.50 * *$ & 13.83 & 11.67 \\
\hline & \pm 2.61 & \pm 5.04 & \pm 3.22 & \pm 2.43 & \pm 1.94 & \pm 1.97 \\
\hline \multirow[t]{2}{*}{ CRP (mg.dl $\left.{ }^{-1}\right)$} & 196.00 & 182.00 & 252.00 & -66.00 & 444.00 & 150.00 \\
\hline & \pm 156.58 & \pm 677.14 & \pm 654.28 & \pm 304.50 & \pm 802.87 & \pm 646.30 \\
\hline
\end{tabular}

Mean values and standard deviations of change in biochemical markers

$* *$ Statistically significant $(p<0.05)$ from post-exercise

tepid water (control group, $24^{\circ} \mathrm{C}$ ) in 40 untrained volunteers immediately after eccentric quadriceps exercise. No significant differences were observed between groups with regard to changes in most pain parameters, tenderness, isometric strength, swelling, hop-for-distance, or serum CK over time. There was a significant difference in subjective pain during sit-to-stand tests at $24 \mathrm{~h}$, with the intervention group demonstrating a greater increase in pain than the control group. This study used the same temperature as we used $\left(5^{\circ} \mathrm{C} \pm 1^{\circ}\right)$ and similar time of immersion, however the authors also did not find any significant effects for CWIT. Further studies are needed to test the influence of different parameters of CWIT.

Blood lactate levels and CK activity decreased significantly after treatment with LEDT in our study. Previous studies from our research group have shown positive results by decreasing CK activity $[28,29]$ and blood lactate levels [29] when LEDT was performed before exercise. However, the results of this study are novel since LEDT was performed immediately after the exercise test.

The observed decrease in blood lactate levels after LEDT in this study may have been caused by an increase in microcirculation previously observed in healthy muscle tissue after LLLT [31]. This could also contribute to the observed decrease in CK activity.

Previous studies with red and infrared LLLT have shown reduction of reactive oxygen species (ROS) release and creatine phosphokinase activity, increase in levels of antioxidants and heat shock proteins [32, 33], improvement in mitochondrial function [34], an increase in ATP synthesis, and in mitochondrial respiratory chain [35]. These effects at the cellular level could possibly be responsible for the decrease in $\mathrm{CK}$ activity after treatment as observed in this study.

Lactate accumulation is a good indirect indicator of increases in $\mathrm{H}^{+}$protons and decreases in blood and cellular $\mathrm{pH}$, which lead to metabolic acidosis [6], and activityrelated changes in CK plasma enzyme activity can indicate an emerging state of muscle damage [11]. Therefore, enhancement of these biochemical markers can indicate an increased risk to injuries, and positive effects observed in blood lactate levels and CK activity after LEDT indicates a faster recovery after exercise test.

There is an increasing amount of clinical evidence about the effects of LLLT [36]. Typical therapeutic LLLT devices have small spot sizes $\left(0.001\right.$ to $\left.1 \mathrm{~cm}^{2}\right)$, high irradiance $\left(0.05\right.$ to $\left.5 \mathrm{~W} / \mathrm{cm}^{2}\right)$ and a narrower bandwidth $( \pm 3 \mathrm{~nm})$ than LEDT devices ( \pm 6 to $20 \mathrm{~nm}$ ). In the laboratory, LLLT devices seem to inflict a better anti-inflammatory effect than LEDT [37]. However, in situations where larger areas of muscle tissue need to be irradiated, multidiode LEDT may be a good compromise for their larger spot size and lower costs. It is known that phototherapy with infrared wavelengths penetrates better through the human skin than

Table 3 Responder analysis

\begin{tabular}{|c|c|c|c|c|c|c|}
\hline & \multicolumn{2}{|l|}{ Placebo } & \multicolumn{2}{|l|}{ LEDT } & \multicolumn{2}{|l|}{ CWIT } \\
\hline & Responders & Non-responders & Responders & Non-responders & Responders & Non-responders \\
\hline $\mathrm{CK}$ & 4 & 2 & 6 & 0 & 4 & 2 \\
\hline Lactate & 2 & 4 & 6 & 0 & 4 & 2 \\
\hline CRP & 3 & 3 & 3 & 3 & 3 & 3 \\
\hline Total & 9 & 9 & 15 & 3 & 11 & 7 \\
\hline
\end{tabular}


red wavelengths [38]. With this perspective in mind, the positive results observed in this study should be due to the association of effects of red and infrared light. Red diodes could promote increased microcirculation in skin, and infrared diodes could increase ATP synthesis and decrease oxidative stress in exercised muscles, leading to improvement in short-term recovery. However, the exact mechanisms through each wavelength acts still need further investigation.

We also observed that the relative risk for a positive response was significant $(p=0.05)$ for active LEDT over placebo, but there were no significant differences for any of the other treatment comparisons (Table 3). The response pattern to placebo treatment may be due to the rest in supine/prone position for $5 \mathrm{~min}$. However, this needs further investigation.

We have previously observed that LEDT before exercise decreased the post-exercise CRP levels [29]. However, in this pilot study we observed a tendency for decreasing CRP levels after LEDT without statistical significance, probably because of our small sample size and large standard deviation. We tried to recruit more volunteers for the study, but this was not possible because only six volunteers met the inclusion criteria and performed all exercise sessions, leading to a reduced sample size. As far as we know, biochemical markers have a large variability, leading to outcomes with large standard deviations as we observed in our study (Table 2). For this reason, we recruited volunteers from the same sport activity and same team in an effort to make our sample more homogenous. The largest problem with the small sample size is the risk of inflicting type II errors where true differences among interventions are not detected because of low statistical power [39]. The lack of influence on post-treatment CRP levels in the LEDT group may also be the result of too low statistical power. Therefore, this question needs further investigation in larger samples before firmer conclusions can be drawn.

\section{Conclusions}

Five minutes of LEDT with the parameters employed in this study was more effective than placebo LEDT to reduce levels of some biochemical markers that are related to muscle recovery after a Wingate cycle test. We found no significant effect of CWIT with the used parameters over placebo LEDT. The effectiveness of CWIT to enhance muscle recovery remains uncertain, and further studies are needed to test CWIT with different parameters. LEDT seems to be a potential tool to improve muscle recovery after exercises. However, further studies are needed to test their LEDT effects after different exercise tests and if LEDT has a possible influence on performance during the recovery period.

Ethical Standards This research follows the current Brazilian laws of experiments with humans.

Conflict of Interest The authors declare that they have no conflicts of interest.

Open Access This article is distributed under the terms of the Creative Commons Attribution Noncommercial License which permits any noncommercial use, distribution, and reproduction in any medium, provided the original author(s) and source are credited.

\section{References}

1. Tessitore A, Meeusen R, Cortis C, Capranica L (2007) Effects of different recovery interventions on anaerobic performances following preseason soccer training. J Strength Cond Res 21:745-750

2. Tessitore A, Meeusen R, Pagano R, Benvenuti C, Tiberi M, Capranica L (2008) Effectiveness of active versus passive recovery strategies after futsal games. J Strength Cond Res 22:1402-1412

3. Halson SL, Quod MJ, Martin DT, Gardner AS, Ebert TR, Laursen PB (2008) Physiological responses to cold water immersion following cycling in the heat. Int $\mathrm{J}$ Sports Physiol Perform $3: 331-346$

4. Barnett A (2006) Using recovery modalities between training sessions in elite athletes: does it help? Sports Med 36:781-796

5. Westerblad H, Allen DG, Lannergren J (2002) Muscle fatigue: lactic acid or inorganic phosphate the major cause? News Physiol Sci 17:17-21

6. Cairns SP (2006) Lactic acid and exercise performance: culpid or friend? Sports Med 36:279-291

7. Ahmaidi S, Granier P, Taoutaou Z, Mercier J, Dubouchaud H, Prefaut C (1996) Effects of active recovery on plasma lactate and anaerobic power following repeated intensive exercise. Med Sci Sports Exerc 28:450-456

8. Martin NA, Zoeller RF, Robertson RJ, Lephart SM (1998) The comparative effects of sports massage, active recovery, and rest in promoting blood lactate clearance after supramaximal leg exercise. J Athl Train 33:30-35

9. Baldari C, Videira M, Madeira F, Sergio J, Guidetti L (2004) Lactate removal during active recovery related to the individual anaerobic and ventilatory thresholds in soccer players. Eur J Appl Physiol 93:224-230

10. Cheung K, Hume P, Maxwell L (2003) Delayed onset muscle soreness: treatment strategies and performance factors. Sports Med 33:145-164

11. Houmard JA, Costill DL, Mitchell JB, Park SH, Fink WJ, Burns JM (1990) Testosterone, cortisol, and creatine kinase levels in male distance runners during reduced training. Int J Sports Med 11:41-45

12. MacDougall JD, Hicks AL, MacDonald JR, McKelvie RS, Green HJ, Smith KM (1998) Muscle performance and enzymatic adaptations to sprint interval training. J Appl Physiol 84:2138-2142

13. Fallon KE, Sivyer G, Sivyer K, Dare A (1999) The biochemistry of runners in a 1600-km ultramarathon. Br J Sports Med 33:264-269

14. Fehrenbach E, Niess AM, Schlotz E, Passek F, Dickhuth HH, Northoff $\mathrm{H}$ (2000) Transcriptional and translational regulation of 
heat shock proteins in leukocytes of endurance runners. J Appl Physiol 89:704-710

15. Peake JM, Nosaka K, Suzuki K (2005) Characterization of inflammatory responses to eccentric exercise in humans. Exerc Immunol Rev 11:64-85

16. Peake JM, Nosaka K, Muthalib M, Suzuki K (2006) Systemic inflammatory responses to maximal versus submaximal lengthening contractions of the elbow flexors. Exerc Immunol Rev 12:72-85

17. Malm C, Sjodin TL, Sjoberg B, Lenkei R, Renstrom P, Lundberg IE, Ekblom B (2004) Leukocytes, cytokines, growth factors and hormones in human skeletal muscle and blood after uphill or downhill running. J Physiol 556:983-1000

18. Milias GA, Nomikos T, Fragopoulou E, Athanasopoulos S, Antonopoulou S (2005) Effects of eccentric exercise-induced muscle injury on blood levels of platelet activating factor (PAF) and other inflammatory markers. Eur J Appl Physiol 95:504-513

19. Sellwood KL, Brukner P, Williams D, Nicol A, Hinman R (2007) Ice-water immersion and delayed-onset muscle soreness: a randomised controlled trial. Br J Sports Med 41:392-397

20. Howatson G, Goodall S, van Someren KA (2009) The influence of cold water immersions on adaptation following a single bout of damaging exercise. Eur J Appl Physiol 105:615-621

21. Weerapong P, Hume PA, Kolt GS (2005) The mechanisms of massage and effects on performance, muscle recovery and injury prevention. Sports Med 35:236-256

22. Coffey V, Leveritt M, Gill N (2004) Effect of recovery modality on 4-hour repeated treadmill running performance and changes in physiological variables. J Sci Med Sport 7:1-10

23. Gill ND, Beaven CM, Cook C (2006) Effectiveness of post-match recovery strategies in rugby players. Br J Sports Med 40:260-263

24. Dowzer CN, Reilly T, Cable NT (1998) Effects of deep and shallow water running on spinal shrinkage. Br J Sports Med 32:44-48

25. Lattier G, Millet GY, Martin A, Martin V (2004) Fatigue and recovery after high-intensity exercise. Part II: Recovery interventions. Int J Sports Med 25:509-515

26. Wilcock IM, Cronin JB, Hing WA (2006) Physiological response to water immersion: a method for sport recovery? Sports Med 36:747-765

27. Leal Junior EC, Lopes-Martins RA, Baroni BM, De Marchi T, Taufer D, Manfro DS, Rech M, Danna V, Grosselli D, Generosi RA, Marcos RL, Ramos L, Bjordal JM (2009) Effect of 830-nm low-level laser therapy applied before high-intensity exercises on skeletal muscle recovery in athletes. Lasers Med Sci 24:857-863

28. Leal Junior EC, Lopes-Martins RA, Baroni BM, De Marchi T, Rossi RP, Grosselli D, Generosi RA, de Godoi V, Basso M,
Mancalossi JL, Bjordal JM (2009) Comparison between singlediode low-level laser therapy (LLLT) and LED multi-diode (cluster) therapy (LEDT) applications before high-intensity exercise. Photomed Laser Surg 27:617-623

29. Leal Junior EC, Lopes-Martins RA, Rossi RP, De Marchi T, Baroni BM, de Godoi V, Marcos RL, Ramos L, Bjordal JM (2009) Effect of cluster multi-diode light emitting diode therapy (LEDT) on exercise-induced skeletal muscle fatigue and skeletal muscle recovery in humans. Lasers Surg Med 41:572-577

30. Leal Junior EC, Lopes-Martins RA, Dalan F, Ferrari M, Sbabo FM, Generosi RA, Baroni BM, Penna SC, Iversen VV, Bjordal JM (2008) Effect of 655-nm low-level laser therapy on exerciseinduced skeletal muscle fatigue in humans. Photomed Laser Surg 26:419-424

31. Tullberg M, Alstergren PJ, Ernberg MM (2003) Effects of lowpower laser exposure on masseter muscle pain and microcirculation. Pain 105:89-96

32. Avni D, Levkovitz S, Maltz L, Oron U (2005) Protection of skeletal muscles from ischemic injury: low-level laser therapy increases antioxidant activity. Photomed Laser Surg 23:273-277

33. Rizzi CF, Mauriz JL, Freitas Correa DS, Moreira AJ, Zettler CG, Filippin LI, Marroni NP, González-Gallego J (2006) Effects of low-level laser therapy (LLLT) on the nuclear factor (NF)-kappaB signaling pathway in traumatized muscle. Lasers Surg Med 38:704-713

34. Xu X, Zhao X, Liu TC, Pan H (2008) Low-intensity laser irradiation improves the mitochondrial dysfunction of $\mathrm{C} 2 \mathrm{C} 12$ induced by electrical stimulation. Photomed Laser Surg 26:197-202

35. Silveira PC, Silva LA, Fraga DB, Freitas TP, Streck EL, Pinho R (2009) Evaluation of mitochondrial respiratory chain activity in muscle healing by low-level laser therapy. J Photochem Photobiol B 95:89-92

36. Chow RT, Johnson MI, Lopes-Martins RA, Bjordal JM (2009) Efficacy of low-level laser therapy in the management of neck pain: a systematic review and meta-analysis of randomised placebo or active-treatment controlled trials. Lancet 374:18971908

37. de Morais NC, Barbosa AM, Vale ML, Villaverde AB, de Lima CJ, Cogo JC, Zamuner SR (2009) Anti-inflammatory effect of low-level laser and light-emitting diode in Zymosan-induced arthritis. Photomed Laser Surg 28:227-232

38. Enwemeka CS (2009) Intricacies of dose in laser phototherapy for tissue repair and pain relief. Photomed Laser Surg 27:387-393

39. Biau DJ, Kernéis S, Porcher R (2008) Statistics in brief: the importance of sample size in the planning and interpretation of medical research. Clin Orthop Relat Res 466:2282-2288 